\title{
Techno-Microbial Hazards Associated with CKs: Public Health Risk and Policy Implications in Nigeria
}

\author{
Awole ye O M, Ogunkanbi D A, Ayo-Lawal R, A Ade wole G O, Elufisan T O* \\ National centre for Technology Management Obafemi Awolowo University Ile Ife PMB 012 Nigeria
}

\begin{abstract}
The role of personal computer (PC) and its associated accessories in this present knowledge-based global economy cannot be overemphasized. Its application is highly significant being a tool for the transfer of information world wide, this consequently resulted in an increase in the rate at which the public interact with it. Computer system has been identified as formites which could serve as a portal through which pathogens can be transmitted among user. An essential part of a PC is the keyboard; certain microbes have been isolated from the surface of computer keyboard (CK) which had been linked with many infections and disease conditions. The need to identify the possibilities of CK to act as a reservoir host for the transmission of this pathogenic organism to ambient users led to this study. This study aimed to review the role CKs play in the transfer of pathogens in Nigeria and to sensitize Nigerian on the possibilities of contacting infectious diseases through CKs. This paper also provides policy recommendations on the necessary measures that could be adopted to minimize such infections.
\end{abstract}

Keywo rds Computer, Mouse, Keyboard, Nosocomial, Formites, Microorganisms

\section{Introduction}

The use of computer and its associated accessories are becoming inevitable in a world of various technological and informational transformations[1]. Nowadays, computer has got application in various fields of knowledge, workplaces and disciplines so much that, its importance cannot be undermined because almost all of the operations are directly dependent on computer usage. Owing to this indispensable nature of computer to the various activities of man in this technologically dominated society, there is increasing rate of interactions with computer from day to day[2-4].

In Nigeria, a serious and renewed interest in public health has taken unusual dimensions. This is because of the recent reoccurrence of emerging and re-emerging epidemics with common or familiar etiological agents (cholera outbreaks, $E$. coli outbreak, diarrhoea, Lasa fever, polio, etc.) in the country despite national efforts and international supports. Even though there are many factors and conditions that may elic it the above, however, no national epidemiological data is available on keyboards as a medium of infections and disease spread. It has been established that irrespective of the benefits of computer, that there are public health risks associated with their usage[7] due to human interactions. Several discussions have been raised with respect to the

* Corresponding author:

ptemidayo@gmail.com (Elufisan T O)

Published online at http://journal.sapub.org/ijis

Copyright (C) 2012 Scientific \& Academic Publishing. All Rights Reserved health related threat linked with the continuous use of computer. The observed danger had on the long run been related to health hazard involving irradiation wave emanating from the computer system, visual related risk associated with the continuous use of computer[8] and lately, its impacts on the fingers anatomy and sitting positions.

The intrinsic ability of some pathogens to survive in adverse environmental conditions such as extreme temperature, $\mathrm{pH}$, low oxygen pressure, and in the presence of little or no nutrient and their ubiquitous nature[9,21] inform researchers of the need to investigate computer systems and especially the keyboards as media in infections transmission. It has been reported that computer may act as a reservoir for the transmission of potentially hazardous or pathogenic microorganisms [4]. These pathogenic microorganis ms include bacteria, fungi, protozoan, viruses, chlamydia, and rickettiziae. Each of these organisms has developed one or more mechanis ms of colonization and survival in any environment. They have been reported to cause $98 \%$ of infections and diseases. Examples are Staphylococcus species, Klebsiella, Pseudomonas, Escherichia coli, Listeria, and Candida sp, Yesinia, Mycoplasma, Corynebacterium, diphtheria etc.

Computer accessories in particu lar keyboards and mouses are of high preference and have been implicated in most cases as agent of infection transmission both in the community and in the hospitals environment. This is because they are the accessories with the highest level of interaction and are thus potential reservoir of the common 
pathogens that could be isolated from man as mentioned above. The fact that many of these microorganisms have been established to be resistant to common antibiotics poised national catastrophe. There is presently no technological framework and model of tackling this new challenge to health and innovations since computers are not routinely disinfected, then the opportunity for the transmission of contaminating microorganisms is potentially great. This paper therefore examines the various ways through which $\mathrm{CK}$ could act as a portal of microbial infections. The level of awareness of CKs as media of infection was also discussed in this paper. Some technological models that could be adopted to minimize infection spread through CKs are also recommended.

\subsection{Role of Computer in Infection Spread}

This section describes the role of $\mathrm{CK}$ as formites of infection spread.

Computer has been described as the latest technological media which are capable of receiving and accepting data, and performing operation according to instruction (program), and providing result of the operation with great speed and accuracy[10]. The importance of computer had been identified in various sectors such as health, agriculture, finance, education and research institutes[2]. Its pace of operation has made its application in these fields inevitable. The inevitability of computer in most of the identified fields has been a major factor for the continuous proliferation of computer usage in all of these fields.

Computers continue to have an increased presence in almost every aspect of our occupational, recreational, and residential environments[4]. As the popularity of this facility increases, it has been discovered that computer equipment may act as a reservoir for the transmission of potentially hazardous or pathogenic microorganisms due to human and environmental interactions.

Healthcare-associated infections are an important cause of morbidity and mortality in hospitals. Yearly more than 2 million patients acquire healthcare-associated infections, resulting in 90,000 deaths and healthcare costs that are estimated to exceed $\$ 5$ billion[11].

Computer and its accessories such as keyboards and mouses have been implicated in most cases as agent of infection transmission both in the community and in the hospitals environment. Computers are being increasingly used in medical facilities and keyboards and mouse are also a source of potentially lethal bacteria, viruses and infections between users[12]. Computers are ubiquitous in different units of medical settings, for instance, in laboratory where investigations are accessed, radiologic findings are viewed, and computerized physician order entry is performed[20] as well as record departments.

Not only in the health sector, has the computer got application, but also in various other sectors of the economy. This suggests the possibilities of the public contacting some of the infectious diseases that had been identified with CK.

Formites or inanimate objects have been identified with the potential characteristics of serving as a reservoir for microorganis ms and their spores hence the possibility of contacting these microbes or their spore through the use of these agents. Computer is a form of inanimate object that have also been identified as a reservoir that host microbes or microbial spores[4]. Brusse et al.,[13] established computer as a reservoir for microbes and it is being linked to Nosocomial infections in hospital environment. Similarly, the findings of Hubar and Pelon,[14] O'Donnell et al.,[15]; Palenik and Hughes,[16] established the possibilities of contacting infection through the use of computer in health care environment. The work of Hirsch,[17] shows the contamination of the office environments including $\mathrm{CK}$ with bacteria. Anderson and Palombo,[4] found out that multiple-user computer workstations had significantly higher number of pathogenic microorganisms compared with workstations used by predominately one person. He also showed that microbial contamination also occurs on computer equipment located in a large university environment.

CKs and mouses are central to computer as a reservoir of pathogenic microorganisms capable of causing in fections in users with capacity to transmit to other users or non users in the community through interaction in Australia[4] Pathogenic microorganisms such as bacteria, protozoa cysts, and even fungi, their spores and bacteria spores have been identified on computer[1] Multiple studies have shown that CKs could harbour several colon ies of bacteria; for instance a study conducted at the Henry Ford Hospital in Detroit showed that keyboards located in triage and registration areas were more contaminated with bacteria than those in other areas of the emergency department (ED). In their study, seventy-two standards, non-silicone rubber keyboards were swabbed on two different days, six days apart. All keyboard keys, except the function keys, were cultured and analysed for bacteria. The results showed that less than 14 percent, or 10 keyboards, were colonized with nine different bacteria. Of the keyboards in non-treatment areas, nearly 32 percent were contaminated, versus less than 9 percent in treatment (ICT). This is in close connection with the study which suggested that CKs may contribute to cross-transmission because of acquisition of transient hand carriage by healthcare personnel during contact with the contaminated CK surface[8, 4]

Forbes reports that harmful bacteria can linger on CKs in hospitals, making it easy for the germs to spread to patients.[12]

Two studies have also provided evidence linking computer use to cross-contamination of patients, concern has been raised that contact with contaminated CKs might serve as a means for contaminating the hands of healthcare workers with potential pathogens, thereby leading to crosscontamination of patients.[8,4] Schultz et al.,[17] also demonstrated that microbial contamination of CKs was prevalent and that commensals skin organisms were the most common contaminating microbes. It was also reported that the degree of contamination was high enough to 
potentially allow transmission via contaminated hands.

In this century, resistance among pathogenic microbes is unabatedly increasing, hence fast eroding the earlier success experienced at the onset of antibiotic and antibacterial discoveries. The antibiotic and antimicrobial resistances increase cost and epidemic chances within the community or society. Pandey et al.,[18] reported methicilin-resistance Staphylococcus aureus (MRSA) and, Coagulase negative Staphylococcus aureus (CONS) and Corynebacterium species (Diptheroids). Anderson and Palo mbo,[4] reported the presence of pathogenic Enterobacteriaceae in community workplace.

\section{Awareness Level of the Spread of Pathogenic Microbes and Infections via CK}

This section examines details on the awareness level on the possibilities of $\mathrm{CK}$ to spread microbial pathogens. Having established from literatures that CKs are capable of hosting pathogenic microbes, and hence serve as portal of infection (Table 1), it is essential to identify the extent to which the public who continually interact with CKs are aware of the risk associated with its possibilities as a portal of infection. The paucity of literature on this issue necessitate the need to inform users about the risk associated with this inevitable technological tools that is becoming almost unavoidable in a developing society like Nigeria. So much as computer system is a good technological tools, it also has the possibilities of transferring microbial infection from one individual to another. Several reports have revealed the possibilities of
CK being a medium for infection transfer. A recent report in the USA linked the prevalence of nosocomial infection or cross contamination from the hospital to the computers often used for diagnosis in the hospital[19]. The outcome of some studies in the United States revealed the isolation of various species of bacteria, fungi and fungal spores[1]. Another study in the United States revealed that CK contributes significantly to the spread of hospital acquired infection; it was estimated to be responsible for about twenty-five percent of microbes as sociated with nosocomial infection (20). Despite these findings the rate of interaction with CK has remained on the high side because CK has got applications in various economic sectors. This thus increases the risk of contacting some of the infectious organisms associated with CK surfaces. The public are exposed to this risk unconsciously because of the low level of awareness among users of computers in all sectors, in particular education and health sectors, this thus serve as a medium to inform users of keyboards of the need to be more care ful as they interact with this technological gadget. There may be need to exchange computers among users in a work place, cyber café as well as other public domain this can serve as a means of transferring microbes as well as infections amidst users.

\section{Microbes Associated with Computer Surfaces}

A list of microbes has been identified to be associated with CKs, this section highlights group of microbes that had been isolated from keyboard and has been linked to various infections.

Table 1. Sites sampled for the presence of bact eria and percentage cont amination

\begin{tabular}{|c|c|c|c|c|c|c|}
\hline Site & & Home & Office & \multicolumn{2}{|l|}{ Internet Café } & Total\% \\
\hline \multirow[t]{3}{*}{ CK } & Number of sample & 25 & 25 & 50 & & \\
\hline & Percentage Contamination & 88 & 92 & 100 & & \\
\hline & \multicolumn{2}{|l|}{ TotalPercentage } & & & & 93 \\
\hline \multirow[t]{3}{*}{ Computer mice } & Number of sample & 25 & 25 & 50 & & \\
\hline & Percentage Contamination & 91 & 91 & 100 & & \\
\hline & \multicolumn{2}{|l|}{ TotalPercentage } & & & & 97 \\
\hline \multicolumn{2}{|l|}{ Shopping cart } & SuperMarket1 & SuperMarket2 & SuperMarket3 & \multicolumn{2}{|c|}{ SuperMarket4 Total\% } \\
\hline & Number of sample & 25 & 25 & 25 & 25 & \\
\hline & Percentage Contamination & 89 & 95 & 95 & 92 & \\
\hline & \multicolumn{2}{|l|}{ TotalPercentage } & & & & 97 \\
\hline \multicolumn{2}{|l|}{ Elevat or button } & Shopping Mall & \multicolumn{2}{|c|}{ Residential home } & & Total\% \\
\hline & Number of sample & 50 & 50 & & & \\
\hline & Percentage Contamination & 96 & 98 & & & \\
\hline & \multicolumn{2}{|l|}{ TotalPercentage } & & & & 97 \\
\hline
\end{tabular}

Adapted from Al-Ghamdi et al. 2011 
Keyboard use has been on the increase and the high rate of unhygienic interaction with the computer made them a potential reservoir of microbial pathogen[1]. Microorganisms are ubiquitous and have devise various means of survival in any environment and surfaces, including some that do not even provide them with the adequate nutrient for their growth. This ability in microorganis ms enabled them to colonize and remain on the surface of computers and act as formites. Several microorganis ms have been isolated from CK surfaces. One characteristic feature of all these mic robes is that they have peculiar mechanisms in surviving in harsh environmental conditions; such as encysting, encapsulation, spore production and encapsulation. Most of the microorganisms that have been isolated from the CK have been linked with different health related conditions particularly in nosocomial infection. Apart from being associated with hospital acquired infections, this organisms that have been isolated from computers are also common in the community hence the need for caution when exchanging and interacting with computer systems. The common associated organisms include; bacteria (Bacillus species, coagulase negative staphylococcus aureus, oxacillin sensitive Staphylococcus aureus oxacillin resistant staphylococcus aureus, vancomycin sensitive enterococcus, vancomycin resistant enterococcus diphtheroids, Micrococcus species, bacillus species, non fermentative gram negative rod propionibacteria, alpha streptococci, viridans streptococci (Table 2), Fungi and fungal spores. The fungi species that have been linked to $\mathrm{CK}$ are mainly aspergillus species and aspergillus flavus. These microorganisms are associated with various infections that affect human health both systemically and locally[1] Most common diseases associated with these organisms are aspergillosis, respiratory tract diseases, pneumonia, dysentery, cholera. Similarly, Kumar and Sristava 2012 isolated some pathogenic bacteria of various genera from CK. These microbes are member of the genera Streptococcus, Micrococcus and enterococcus and escherichia coli (Table 3)[21]. These organisms have been identified with some serious infection that had been linked with some common infections such as cold, influenza and sore throat. Escherichia coli have been known to be a potential opportunistic pathogen which when the immune system is compromised can cause serious diseases such as traveller's diarrhoea and gastroenteritis. These thus pose CKs as potential agent for the transmission of infection.

Table 2. Bacteria species isolated from the surface of CKs in percentage

\begin{tabular}{|c|c|}
\hline Coagulase-negative staphylococci & 45.0 \\
\hline Gram Positive bacilli & 30.9 \\
\hline Staphylococcus aureus & 10.6 \\
\hline Pseudomonas spp & 5.85 \\
\hline Gram Negative bacilli & 7.44 \\
\hline
\end{tabular}

Adapted and modified from Al-Ghamdi et al. 2011
Table 3. Biochemical characterization of bacterial isolates from $\mathrm{CK}$

\begin{tabular}{|c|c|c|c|c|c|c|c|c|c|}
\hline $\begin{array}{c}\mathrm{S} / \\
\mathrm{No}\end{array}$ & Bacteria & $\begin{array}{c}\mathrm{In} \\
\mathrm{d}\end{array}$ & $\mathrm{MR}$ & $\begin{array}{c}\mathrm{V} \\
\mathrm{P}\end{array}$ & $\mathrm{Cit}$ & $\begin{array}{c}\mathrm{Ur} \\
\mathrm{e}\end{array}$ & $\begin{array}{c}\mathrm{N} \\
\mathrm{R}\end{array}$ & $\begin{array}{c}\mathrm{Ca} \\
\mathrm{t}\end{array}$ & $\begin{array}{c}\mathrm{O} \\
\mathrm{x} \\
\mathrm{i}\end{array}$ \\
\hline 1 & $\begin{array}{c}\text { Staphyl } \\
\text { ococcus } \\
\text { aureus }\end{array}$ & - & + & - & + & - & + & + & + \\
\hline 2 & $\begin{array}{c}\text { Staphyl } \\
\text { ococcus } \\
\text { epidem } \\
\text { idis }\end{array}$ & - & + & + & + & - & + & - & + \\
\hline 3. & $\begin{array}{c}\text { Microco } \\
\text { ccus sp }\end{array}$ & - & - & - & - & - & - & + & + \\
\hline 4 & $\begin{array}{c}\text { Streptoc } \\
\text { occus } \\
\text { sp. }\end{array}$ & - & + & - & + & + & - & + & - \\
\hline 5 & E. coli & - & + & - & + & + & - & + & - \\
\hline
\end{tabular}

Adapted from Kumar and Sristava (2012)

\section{Recommendations}

This section provides possible solution that could be adopted to min imize the spread of pathogens via CK.

Although so much had been said on the role of keyboard as a portal of infection, there are no special measures put in place to control the spread of pathogenic microbes through the use of CKs. A major proposition is hand washing which many may not adhere to because of the urgency of their assignment. Other recommendations that could be adopted include:

- replacement of traditional keyboards with silicone rubber models.

- use of infection-resistant keyboards which are completely flat and covered with an hypoallergenic material resistant to bug growth.

- use of keyboards-timed warning light which can be configured to meet the needs of different environments. The warning lights would go out when all the sensors are activated, indicating that the keyboard is clean.

These techniques are presently expensive and may not be cheaply comeby; hence government and private sectors intervention is essential in funding further research, development and innovations along this line.

\section{Conclusions}

In conclusion, computer has been found to contribute significantly to high incidence of microbial resistance. This is because it could harbor various microorganisms in its crevices and space for a longer period of time. An increase in resistance often lead to an increase in treatment cost and thus may result or lead to a decrease in national GDP and GNP. It is therefore essential that technological strategy be adopted to minimize the spread of microbial infection through CK. 


\section{REFERENCES}

[1] William A., Rutala, M.S., Maria W.F., Gergen, M.T., David J. Weber, MD, (2006). Bacterial Contamination of Keyboards: Efficacy infection control and hospital epidemiology, vol. 27(4).

[2] Onasanya S.A. (2002). The impact of computer in a developing country like Nigeria: Nigerian Journal of Research and Production (NIJOREP) Vol. 1.

[3] Balci, M. Namuslu, M. Devrim İ, Durak, E. (2009). Effects of computer monitor-emitted radiation on oxidant/ antioxidant balance in cornea and lens from rats; Molecular Vision, 15:2521-2525.

[4] Anderson, G., Palombo, E. (2009). Microbial contamination of CKs in a university setting. Am J Infect Control, 37:507509.

[5] Flemming, J. (2007). CK a new reservoir for infection transmission; Nursing and Patient Care

[6] Rybicki, E.P., (1990). The classification of organism at the life edge of life or problems with virus systematic. S.Africa.jour.Sci., 86:182-186

[7] Lwoff, A. (1957). The concept of Virus. J.Gen-microbiol, $17(2): 239-53$

[8] Brightman, W., and Dunsdale M., (1986). Using Computers in an Information Age. Albany, New York: Dclmar Publishers Inc.

[9] Burke JP. Infection control-a problem for patient safety. N Engl J Med 2003; 348:651-656. Cozanitis, D., Grant, J., Makela, P. (1978). Bacterial contamination of telephones in an intensive care unit. Anaesthesist, 27:439.

[10] QOT (http://www.quickonlinetips.com/archives/2005/04/ computer-keyboards-spread-infections-bacteria)

[11] Bures S, Fishbain JT, Uyehara CF, Parker JM, Berg BW. $\mathrm{CKs}$ and faucet handles as reservoirs of nosocomial pathogens in the intensive care unit. Am J Infect Control $2000 ; 28: 465-471$.

[12] Hubar J.S., Pelon W., (2005). Low-cost screening for microbial contaminants in aerosols generated in a dental office. Gen Dent, 53:270. ICT (http://www.infectioncontrolt oday.com/galleries.aspx

[13] O’Donnell M.J., Tuttlebee C.M., Falkiner F.R., Coleman DC. (2005). Bacterial contamination of dental chair units in a modern dental hospital caused by leakage from suction system hoses containing extensive biofilm. J Hosp Infect, 59:348.

[14] Palenik C.J., Hughes E.A., (2005). Microbial contamination of CKs and mice present in dental clinics. Am J Infect Control,36: E23.

[15] Hirsch, S. (2005). Germs are working overtime at the office. (www.latimes.com). Los Angeles Times, February 28, 2005. Available at: http://www.latimes.com/2005/feb/28/health/he - germs28. Accessed September 8, 2008

[16] Neely AN, Maley MP, Warden GD. CKs as reservoirs for Acinetobacter baumannii in a burn hospital. Clin Infect Dis $1999 ; 29: 1358-1360$.

[17] Schultz M, Gill J, Zubairi S, Huber R, Gordin F. Bacterial contamination of CKs in a teaching hospital. Infect Control Hosp Epidemiol 2003; 24:302-303.

[18] Anastasiades, P Pratt, TL, Rousseau, LH Steinberg, WH, Joubert G. 2009. Staphylococcus aureus on computer mice and keyboards in intensive care units of the Universitas Academic Hospital, Bloemfontein, and ICU staff's knowledge of its hazards and cleaning practices. South Afr J Epidemiol Infect 2009; 24(2):22-26

[19] Pandey, A., Das, A., Kansal, R., Asthana, A., and Madan. M. (2011). Annals of Biological Research, 2 (2):111-115

[20] William A R, Matthew, S., White, M F., Gergen, MT (ASCP), David J W (2009). Bacterial Contamination of Keyboards: Efficacy and Functional Impact of Disinfectants. Infect control Hosp. Epidemiol: 2006, 27.372:377

[21] Kumar A. and Sristava, M 2012 Computer components in college and its surroundings encompass the pathogenic bacteria: Journal of Applied Science and Environmental sanitation; Vol u m e 7, N u m ber 1:43-47, M a r ch, 2012 . 